\title{
The dimensions of hotel customer ratings that boost RevPAR
}

\author{
Marta Nieto-Garciaa, Giuliano Resce ${ }^{\mathrm{b}}$, Alessio Ishizaka ${ }^{\mathrm{a}}$, Nicoletta Occhiocupoc, \\ Giampaolo Viglia \\ aUniversity of Portsmouth, Faculty of Business and Law, Portland Street, PO13DE, Portsmouth, UK \\ ¿Università degli Studi Roma Tre, Department of Economics and Accounting, Via Silvio D'Amico, 77, 00145, \\ Roma, RM, Italy \\ cIQS School of Management, Department of Business and Management, Via Augusta 390, 08017, Barcelona, \\ Spain
}

\begin{abstract}
Online ratings provide valuable information to operators. However, the use of this information for revenue maximization purposes remains at a moot point. This article proposes a new method to decompose ratings based on their relevance to hotel performance. From a methodological standpoint, we propose a multi-criteria decision analysis approach. The empirical validation includes two independent data sources, online ratings from Booking.com and RevPAR data from STR. By means of pairwise comparisons in PROMETHEE, the findings reveal the different weights of individual ratings, helping operators to understand the weight of each rating attribute in terms of revenue maximization. In particular, apart from the importance of the location, the role of staff and facilities emerge as central in terms of revenue maximization. The proposed model offers new theoretical insights on the relevant dimensions, helping hoteliers to prioritize when making trade-off decisions.
\end{abstract}

\section{Keywords}

online ratings; hotel attributes; RevPAR, PROMETHEE, multi-criteria decision analysis 


\section{Introduction}

In recent years review platforms have become a must read before making purchase decisions (Zhu \& Zhang, 2010). Customers rely on this information source, as it is perceived trustworthy and independent (Litvin et al., 2008). Likewise, companies can use this information source to their advantage by learning from customers' evaluations. Many online platforms identify several individual criteria that customers are required to rate and then compute an average of these ratings to show an overall evaluation. For instance, Booking.com presents an overall rating that is an average of various individual ratings. Zoover.com, one of the main social networks specialized in trip reviews, also calculates the overall rating as an average of nine individual ratings. Two main assumptions characterize this aggregation: equal weights and full compensation. The main problem of equal weights aggregation is the absence of differentiation between important and non-important hotel characteristics. Full compensation implies that a hotel could compensate the low score in one aspect with a high score in another. This perfect substitution across hotel dimensions (or attributes) may be far from what actually happens in the consumers' decision making process.

While previous research has widely investigated the effects of overall rating on hotel performance (e.g., Yang, Park \& Hu, 2018; Kim, Lim \& Brymer, 2015; Öğüt \& Taş, 2012), only a few studies have analysed the disaggregated effects of individual ratings on hotel performance (Xie, Zhang \& Zhang, 2014). In addition, there is dearth of research on summarizing individual ratings into a single overall rating. This paper posits that the simplistic use of averages to summarize different individual ratings leads to a non-accurate overall rating.

In order to address this gap, overcoming these limitations, the present study proposes an alternative overall rating model that unveils the role of each attribute in terms of revenue maximization. Specifically, this study introduces a new method to summarize individual ratings using a Multi-Criteria Decision Analysis (MCDA) approach (Greco et al. 2005; Ishizaka \& Nemery, 2013). The solution of a Multi-Criteria problem depends not only on the basic data (individual ratings), but also on the decision-maker preferences. In the MCDA family, PROMETHEE (proposed by Brans \& Vincke, 1985; Brans et al. 1986) allows the inclusion of information that accounts for the decision-maker preferences (preference functions and weights). Stemming from this, we develop a more flexible extension of PROMETHEE that estimates preference functions and weights in a full data-driven process. By relaxing the linearity assumption, the 'compensation effects' (i.e. high rating of a criterion can compensate for the low rating of another criterion), and accounting for different weights of individual ratings, this study entails a methodological contribution going beyond extant research in the field that has relied on the arithmetic average approach.

The resulting model is an innovative mechanism that prioritizes attributes and overcome the simplistic use of an overall average. The proposed overall rating offers new insights on the attributes that are relevant to hotel performance, helping managers prioritize decisions on the delivery of those attributes. The model is flexible in that it updates based on new customers' evaluations and hotel performance data.

\section{Research background}


Markets' digitalization is increasingly relying on user-generated content (UGC). Customers adopt UGC as a trusted source when making purchase decisions (Cheung \& Thadani, 2012; Filieri \& McLeay, 2014, Lee \& Youn, 2009). In the experience goods realm, such as hotel services, the impact of UGC is even more salient, because of the perceived degree of uncertainty prior to consumption (Litvin et al., 2008; Liang, et al., 2013). Reviews and ratings are the most common form of UGC (Chatterjee, 2001) and are particularly influential on travel planning (e.g. Casaló et al., 2015; Filieri \& McLeay, 2014; Liu \& Park, 2015; Sparks \& Browning, 2011).

Online reviews help customers comparing hotel choices and avoid unsatisfactory choices (Cantallops \& Salvi, 2014). Review ratings present a summary of past guests' opinions. This summary evaluation is key as it is used by review platforms to rank hotels and by customers as the main driver of hotel selection (Fang et al., 2016; Viglia et al., 2016). Specifically, from the customer perspective, ratings affect customers' decisions along the whole purchase decision process, from booking intentions (e.g., Ladhari \& Michaud, 2015; Mauri \& Minazzi, 2013) to willingness to pay (Nieto-García et al., 2017). From a managerial perspective, current evidence supports a positive relationship between review rating and online hotel sales (Ögüt \& Tas, 2012, Ye, Law \& Gu, 2009; Ye, Law, Gu \& Chen, 2011).

\subsection{Rating as a heuristic cue in customer purchase decisions}

Reputation is central to build a relationship with customers prior to consumption (Pera \& Viglia, 2016). Previous studies on cognitive effort reveal that customers use heuristics to simplify the decision-making process (Tversky \& Kahneman, 1975; Bettman, Luce \& Payne, 1998). Consistent with dual process models of credibility assessment (Petty \& Cacioppo, 1981), Internet users also rely on peripheral route factors or "heuristic" cues, as they enable them to efficiently process product quality information. As the purchase of a service product is often complex and risky, the decision process occurs in stages becoming a funnel-like process (Sirakaya \& Woodside, 2005). In the information search stage, customers construct a "consideration set" and in the evaluation stage they form a "choice set". Specifically, peripheral cues (e.g. online ratings) are useful in the information search stage whereas central information is influential in the evaluation stage (Baek et al., 2012).

Customers try to reduce the amount of effort spent on making decisions as they have limited time and they need to cope with information load (Dellarocas, 2003). Ratings typically summarize information coming from customer reviews and, as cognitive effort-reducing heuristics, play a main role in online purchase decisions (Zhao et al., 2015; Hu, Koh \& Reddy, 2014; Sparks \& Browning, 2011). Overall ratings constitute an important tool to construct the consideration set in the process of hotel search (Jones \& Chen, 2011). In addition, ratings are the main criterion used for the ordering of listings in online platforms (Ert \& Fleischer, 2016).

In this regard, a key aspect to consider is the way in which review platforms calculate ratings. Two major review platforms in the hospitality context are Booking.com and Tripadvisor.com. In these platforms, individual ratings of past customers are summarized into an overall rating. In Booking.com, customers evaluate six specific dimensions or attributes: cleanliness, comfort, location, facilities, staff, and value for money. Booking.com estimates an overall rating by 
summarizing these individual ratings into an average value. Unlike Booking.com, Tripadvisor.com hotels are then ranked by popularity through an algorithm that considers multiple variables such as the number of user reviews, the values of ratings, and the frequency updates of reviews.

\subsection{The effect of online ratings on hotel performance}

Overall product rating refers to an encompassing score that represents a synthesis of the ratings provided by all customers who have reviewed a product (Filieri \& McLeay, 2014). In the tourism and hospitality context, the overall rating reflects the average evaluation of the hotel based on an aggregation of ratings of specific hotel attributes. Each individual attribute rating represents a single aspect, like service, location, price, room or cleanliness. As mentioned before, customers take ratings into account when evaluating a hotel and review platforms use ratings to rank hotels (Schuckert et al., 2015; Ramanathan \& Ramanathan, 2011; Zhang et al., 2011). It follows that ratings are of primary importance both for visibility reasons and for customer decision making.

The impact of online consumer reviews on different indicators of hotel performance has received substantial research attention. For instance, Ye, Law and $\mathrm{Gu}$ (2009) find a significantly positive relationship between online consumer ratings and hotel room sales. Ye, Law, Gu and Chen (2011) specifically show that a 10\% increase in traveler review ratings boost hotel room sales by more than 5\%. Öğ̈̈t and Taş (2012) report that a $1 \%$ increase in online customer ratings increases sales per room up to $2.68 \%$ in Paris and up to $2.62 \%$ in London. All these studies used the number of reviews as a proxy for hotel room sales. This limitation is partially addressed by Viglia et al. (2016), who report that one-point increase in the review score is associated to an increase in the occupancy rate by 7.5 percentage points. A comprehensive meta-analysis on the effect of eWOM on hotel performance concludes that eWOM elasticity varies depending on the geographical setting, panel data structure, data frequency, performance measurement, and functional form (Yang et al., 2018).

While there is a solid research body that focus on overall ratings on performance, only few studies address the effect of individual ratings on hotel performance, showing often contrasting results. Zhang, Ye and Law (2011) outline the role of "Room quality" and "Location" ratings in determining hotel prices. Rhee and Yang (2015) examine the differences in the comparative importance of six hotel attributes (value, location, sleep quality, rooms, cleanliness, and service) in four US hotel chain brands. De Oliveira Santos (2016) studies the effect of individual ratings on hostels' prices suggesting that "Cleanliness", "Facilities" and "Location" have a positive impact on prices being "Cleanliness" the most relevant. Zhang et al. (2011) find that an incremental star (on a 5-point scale) in customer rating of hotel room quality is linked to a $21 \%$ increase in price. However, considering prices as outcome variable overlooks at another important variable for revenue maximization, i.e., occupancy (Falk \& Hagsten, 2015).

Table 1 presents a brief summary of the relevant literature on online ratings in tourism and hospitality. From a review of this literature it is clear that some individual ratings play a more pivotal role than others. Customers process online ratings very differently depending on the 
specific hotel attributes, which suggests the inadequacy of simple averages. In a recent study, Park and Nicolau (2017) discuss the need of multi-faced criteria to capture the richness of the phenomenon with individual ratings. More importantly, just two studies in Table 1 (i.e., Zhang et al. 2011, Xie et al., 2014) specifically address the impact of individual ratings on hotel performance. 
Table 1. Recent literature on the relevance of online ratings in tourism and hospitality.

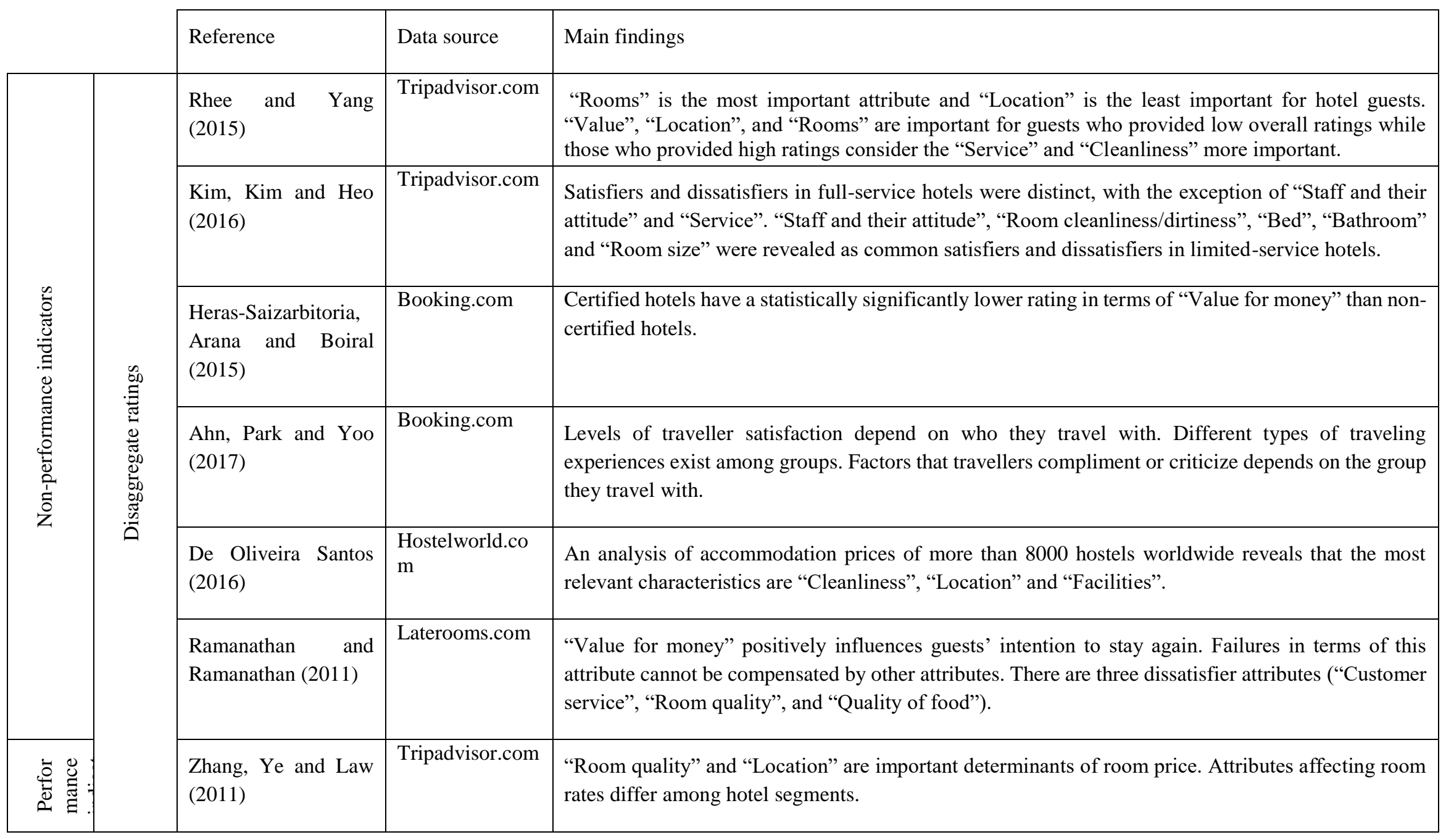




\begin{tabular}{|c|c|c|c|}
\hline & $\begin{array}{l}\text { Xie, Zhang and } \\
\text { Zhang (2014) }\end{array}$ & Tripadvisor.com & $\begin{array}{l}\text { Overall rating and attribute ratings of "Purchase value", "Location" and "Cleanliness" are } \\
\text { significantly associated with hotel performance. Variation and volume of customer reviews moderate } \\
\text { the relationship. }\end{array}$ \\
\hline \multirow{6}{*}{ 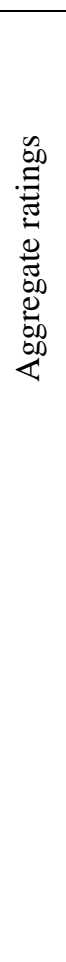 } & $\begin{array}{l}\text { Ye, Law and } \mathrm{Gu} \\
(2009)\end{array}$ & Ctrip.com & $\begin{array}{l}\text { Positive online reviews significantly increase the number of hotel room sales, and the variance of } \\
\text { WOM has a negative impact on the amount of online sales. }\end{array}$ \\
\hline & $\begin{array}{l}\text { Ye, Law, Gu and } \\
\text { Chen (2011) }\end{array}$ & Ctrip.com & $\begin{array}{l}\text { Valence of traveler reviews has a significant impact on the online sales of hotel rooms. Variance in } \\
\text { the valence of rating scores across reviews does not significantly influence the number of online } \\
\text { bookings. }\end{array}$ \\
\hline & Öğüt and Taş (2012) & Booking.com & $\begin{array}{l}\text { Higher customer rating significantly increases the online sales of hotels. In addition, higher customer } \\
\text { ratings result in higher prices of the hotel. }\end{array}$ \\
\hline & Viglia et al. (2016) & $\begin{array}{l}\text { Booking.com } \\
\text { Tripadvisor.com } \\
\text { Venere.com }\end{array}$ & $\begin{array}{l}\text { A one-point increase in the review score leads to an increase in the occupancy rate by } 7.5 \text { percentage } \\
\text { points. The number of reviews has a positive effect on the occupancy rate, but with decreasing returns. }\end{array}$ \\
\hline & $\begin{array}{l}\text { Kim, } \quad \text { Lim and } \\
\text { Brymer }(2015)\end{array}$ & $\begin{array}{l}\text { TripAdvisor, } \\
\text { Priceline, } \\
\text { Hotels.com, } \\
\text { Expedia, and } \\
\text { Yelp }\end{array}$ & $\begin{array}{l}\text { Overall rating is the most salient predictor of hotel performance, followed by response to negative } \\
\text { comments. The higher the overall rating and the higher the response rate to negative comments, the } \\
\text { higher the hotel performance. }\end{array}$ \\
\hline & $\begin{array}{l}\text { Yang, Park and } \mathrm{Hu} \\
(2018)\end{array}$ & Meta analysis & $\begin{array}{l}\text { The major aspects affecting eWOM elasticity are year of study, geographic setting, panel data } \\
\text { structure, data frequency, performance measurement, control of price variable, and function form. }\end{array}$ \\
\hline
\end{tabular}


Following Xie et al. (2014), this study focuses on the Revenue Per Available Room (RevPAR) to evaluate the impact of the different individual ratings on hotel performance. In particular, this research proposes an innovative mechanism that prioritizes attributes and overcomes the simplistic use of an overall average rating. Compared to other performance indicators used in previous literature (e.g., occupancy rate, price and hotel room sales), RevPar is an encompassing performance measure that considers both the level of occupancy of an hotel and the average daily price of the rooms. Moreover, RevPar reflects the operative activity so it is not confounded with financial factors.

\subsection{Aggregating ratings}

The issue of how to synthesize multidimensional information into one metric has recently paved the way to the development of composite indicators (see Nardo et al., 2008; Costanza et al., 2016). As mentioned in Greco et al. (2018), the two more important steps required in the construction of composite indicators are weighting and aggregation.

Regarding the weights, Nardo et al. (2008) list several procedures in the construction of a composite index, with equal weighting being the most frequent solution (Paruolo et al., 2013). This method has been strongly criticized (Decancq \& Lugo, 2013), mainly because it misses to differentiate among important and non-important characteristics.

As far as the aggregation is concerned, the main categorization in the literature is between compensatory and non-compensatory approaches (Munda, 2012). Compensatory approaches assume that a unit can compensate the loss in one dimension with a gain in another (Munda \& Nardo, 2009). Important information can be lost with such a rigid assumption. One of the most important non-compensatory aggregation techniques is PROMETHEE (Brans \& Vincke, 1985; Brans \& De Smet, 2016). As Greco et al. (2018) argue the non-compensatory approaches, despite their benefits, are not popular as aggregation techniques, mainly because these are computationally costly to calculate.

Based on these arguments, the present study proposes a flexible extension of PROMETHEE that reveals the preference/indifference threshold, sets different preference function, and uses a specific weight for each individual rating focusing on revenue maximization.

\section{Methodology}

In a standard multiple criteria decision analysis problem, a set of alternatives is evaluated on a set of criteria. In line with that, the overall rating is an aggregation of some criteria (e.g. individual ratings). The method used in some review platforms (e.g., Booking.com) is a simple average of the evaluation criteria, where the aggregation is fully compensatory (i.e., a hotel could compensate for the low score in one aspect with a high score in another) and does not differentiate between hotels with strengths in different areas. Therefore, granular and important information can be lost in such aggregation. For example, considering two hotels with three equally important criteria, and supposing the ratings of hotel 1 are $H_{-} 1=(5.6,2.5,1.6)$, and the ratings of hotel 2 are H_2 = (4.2,3.0,2.0), the arithmetic average of $H \_1$ is 3.2, while that of H_2 is 3.1. Therefore, H_1 would be superior to H_2. However, the fact that the ratings of two 
criteria of $\mathrm{H} \_1$ are greater than that of $\mathrm{H} \_2$ is completely ignored by this aggregation method. Our approach relaxes four main assumptions compared with the average aggregation: (1) 'compensation effects'; (2) absolute utility in the individual ratings; (3) linearity between the individual ratings and the overall rating; and (4) equal weights of the individual ratings. To this intent, we propose a new overall automatized evaluation based on PROMETHEE (Brans \& Vincke, 1985; Brans et al. 1986). The PROMETHEE method belongs to the family of outranking methods (Ishizaka \& Nemery, 2013). Developed by Brans et al. (1986), PROMETHEE is based on a set of prerequisites (Greco et al. 2005):

1. the difference between the performance of two alternatives must be accounted for;

2. there is no need of an identical scale on all the criteria;

3. three preference relations are possible: alternative $a$ is preferred to alternative $b$, alternatives $a$ and $b$ are indifferent, alternatives $a$ and $b$ are incomparable;

4. the method should be easily understandable by the decision makers;

5. weights must be assigned in a flexible manner.

In the standard PROMETHEE method the assessment procedure requires from decision makers two sources of information: information between the criteria (weights) and information within each criterion (preference functions). The main change proposed here to the standard PREOMETHEE is to retrieve both sources of information by means of an optimization process from collected data.

Formally, we have $n$ alternatives in the set $A=\left\{a_{1}, \ldots, a_{n}\right\}$ which have been evaluated on $m$ criteria in the set $F=\left\{f_{1}, \ldots, f_{m}\right\} . f_{k}\left(a_{i}\right)$ denotes the evaluation of the alternative $a_{i}$ on the criterion $f_{k}$. For each ordered pair of alternatives $\left(a_{i}, a_{j}\right)$, and for each criterion $\left(f_{k}\right)$, the decision maker expresses their preference by means of the unicriterion preference function $P_{k}\left(a_{i}, a_{j}\right)$. The unicriterion preference function $P_{k}\left(a_{i}, a_{j}\right)$ is a function of the difference between the alternative $a_{i}$ and the alternative $a_{j}$ on the criterion $k$, i.e. $f_{k}\left(a_{i}\right)-f_{k}\left(a_{j}\right)$. It is expressed in a number between 0 and 1 that indicates to what extent the alternative $a_{i}$ is preferred or not to the alternative $a_{j}$ on the criterion $f_{k}$. Several typical shapes of preference function are proposed (Brans and Vincke, 1985): the linear, the level, and the Gaussian preference function.

The level preference function can be represented as:

$$
P_{k}\left(a_{i}, a_{j}\right)=\left\{\begin{array}{ccc}
0 & \text { if } & f_{k}\left(a_{i}\right)-f_{k}\left(a_{j}\right) \leq q \\
1 / 2 & \text { if } & q<f_{k}\left(a_{i}\right)-f_{k}\left(a_{j}\right)<p \\
1 & \text { if } & f_{k}\left(a_{i}\right)-f_{k}\left(a_{j}\right) \geq p
\end{array}\right.
$$

Where $p$ is the preference threshold and $q$ is the indifference threshold. In other words, with function (1) it is assumed that the preference of alternative $a_{i}$ over the alternative $a_{j}$ is zero if the difference between criteria is below the indifference threshold, it is 0.5 if the difference 
between criteria is between the indifference and the preference threshold, and it is maximum (i.e. 1) if the difference between criteria is above the preference threshold.

The linear preference function can be represented as:

$$
P_{k}\left(a_{i}, a_{j}\right)=\left\{\begin{array}{ccc}
0 & \text { if } & f_{k}\left(a_{i}\right)-f_{k}\left(a_{j}\right) \leq q \\
\frac{\left[f_{k}\left(a_{i}\right)-f_{k}\left(a_{j}\right)-q\right]}{(p-q)} & \text { if } & q<f_{k}\left(a_{i}\right)-f_{k}\left(a_{j}\right)<p \\
1 & \text { if } & f_{k}\left(a_{i}\right)-f_{k}\left(a_{j}\right) \geq p
\end{array}\right.
$$

With function (2) it is assumed that preference of alternative $a_{i}$ over the alternative $a_{j}$ is zero if the difference between criteria is smaller than the indifference threshold, it is proportional to the difference between criteria if the difference is between the indifference and the preference threshold, and it is total (i.e. 1) if the difference is greater than the preference threshold.

Finally, the Gaussian preference function can be represented as:

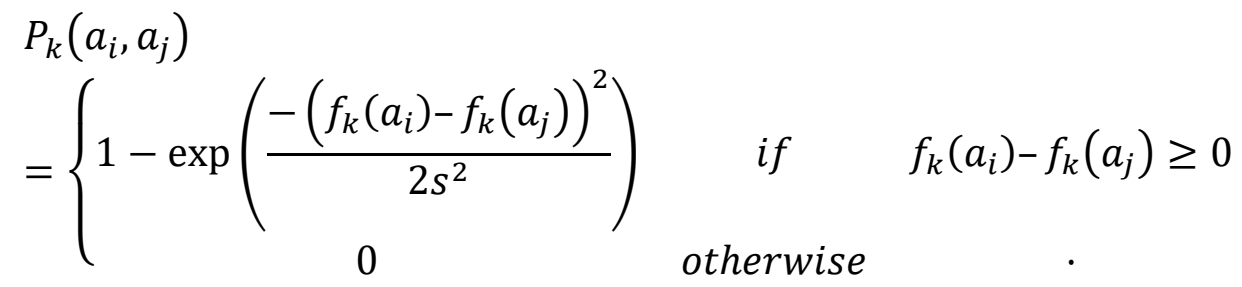

Where $s$ is the inflexion point. With the function (3) it is assumed that the preference of alternative $a_{i}$ over the alternative $a_{j}$ increases more than proportionally until $s$, and it increases less than proportionally over $s$ of difference in criteria.

In the present model we choose the functions on the basis of their ability to forecast a global score (7) as much correlated as possible to hotel performance. More in detail, in the first stage for each criterion $(k)$ and for each alternative $(i)$ we estimate the PROMETHEE unicriterion net flows:

$$
\phi_{k}\left(a_{i}\right)=\frac{1}{n-1} \sum_{j=1}^{n}\left[P_{k}\left(a_{i}, a_{j}\right)-P_{k}\left(a_{j}, a_{i}\right)\right], k=1, \ldots, m
$$

Equation (4) shows a measure of the number of times the $i$-th alternative is preferred over the other alternatives of the set, minus the number of times the $i$-th alternative is being preferred by other alternatives, on the $k$-th criterion. The unicriterion net flows $\left(\phi_{k}\left(a_{i}\right)\right)$ depend on the difference in the raw data $\left(f_{k}\left(a_{i}\right)-f_{k}\left(a_{j}\right)\right)$ and on the preference function $\left(P_{k}\left(a_{i}, a_{j}\right)\right)$. While the differences in raw data are objective, the preference functions are not observable. With the standard PROMETHEE, the decision makers explicitly select the preference functions, but this 
information can be alternatively obtained when the data about the final outcome are available. Therefore, in order to compute an overall rating which better predicts hotel performance, we propose a data-driven algorithm that chooses preference functions that minimize the difference between overall rating (7) and RevPar based on Monte-Carlo simulations. Assuming that we have $N_{k}$ possible preference functions to evaluate, we estimate the unicriterion net flows vectors $\left\{\phi_{k h}(a)\right\}$ for each criterion $(k)$, and for each possible preference function $\left(h_{k}=\right.$ $1, \ldots, N_{k}$ ). These unicriterion net flows are the base of our method of choice. We split the search for optimal setting in multi steps, and we find the optimal setting by means of an iterative algorithm. $^{1}$

Along the same lines, in the standard PROMETHEE the decision makers explicitly select the weights attached to the different criteria with the weights representing the relative importance of the criteria. The proposal in this study is to estimate the weights by linear regression between unicriterion net flows and customer's choice. More specifically, by using the unicriterion net flows (4) we build the unicriterion net flows matrix:

$$
\phi=\left(\begin{array}{ccc}
\phi_{1}\left(a_{1}\right) & \ldots & \phi_{m}\left(a_{1}\right) \\
\vdots & \ddots & \vdots \\
\phi_{1}\left(a_{n}\right) & \ldots & \phi_{m}\left(a_{n}\right)
\end{array}\right)
$$

The matrix $\phi$ has the alternatives on the row and the criteria on the column.

To estimate the weights given to each criterion, we solve the regression (6).

$$
\operatorname{RevPAR}=\alpha+\phi \cdot w+\varepsilon
$$

Where:

- $\boldsymbol{R} \boldsymbol{e v P A R}=\left(\begin{array}{c}\operatorname{RevP} A R_{1} \\ \vdots \\ \operatorname{RevP} A R_{n}\end{array}\right)$ is the vector with proxies of customer's choice;

- $\boldsymbol{\alpha}$ is the intercept vector;

- $\boldsymbol{w}=\left(\begin{array}{c}w_{1} \\ \vdots \\ w_{m}\end{array}\right)$ is the vector of weights;

\footnotetext{
${ }^{1}$ In the first step for each criterion $(k)$ we select the preference function $h_{k}$ that minimizes the differences between unicriterion net flows and RevPar. In the second step, we associate the preference function to the criterion with the lower differences between unicriterion net flows and RevPar. In the third step, given the optimal value of $h_{k}$ for the first criterion, we associate the preference function to the criterion with the second lower differences between unicriterion net flows and RevPar. The $h_{k}$ selected for the second and following criteria, is the preference function thatminimizes the differences between the linear combination among the unicriterion net folws and the unicriteriion net flows previously defined, and RevPAR. The iterative algorithm adds one by one the remaining unicriterion net flows and changes preference functions in order to maximize the predictiveness of final overall rating. Since there is no open source software that implements this version of PROMETHEE, we developed an optimization code in $\mathrm{R}$ that will be send on request of the interested scholars.
} 
- $\boldsymbol{\varepsilon}=\left(\begin{array}{c}\varepsilon_{1} \\ \vdots \\ \varepsilon_{n}\end{array}\right)$ is the error vector.

In the last stage, we estimate the global score as follows:

$$
\phi\left(a_{i}\right)=\sum_{k=1}^{m} \phi_{k}\left(a_{i}\right) w_{k}, i=1, \ldots, n
$$

The global score $\phi\left(a_{i}\right)$ is the proposed overall rating for the $i$-th alternative estimated on the specific criteria. The main difference between the classical PROMETHEE and our model is that we use an automatic search for the optimal setting (preference function and weights), while in the classical PROMETHEE II the preference setting is explicitly chosen by the decision maker.

\section{Empirical application}

Recently Akincilar \& Dagdeviren (2014) implemented PROMETHEE in the hospitality industry to evaluate the quality of a website. The present study also focuses on the hospitality context, specifically providing an empirical application of PROMETHEE using data from Booking.com. A number of reasons support this choice. First, 'Booking.com' is the world leader website in online accommodations, including 1,133,584 active properties in 225 countries and territories (Booking.com, 2017; The Economist, 2017). Second, the number of online monthly visitors has reached 40 million in 2017 (Top 15 most popular, 2017). Third, the overall rating in Booking.com represents an average aggregation of individual ratings, which overlooks at the individual preferences in terms of hotel specific attributes.

The sample includes hotels in three European regions as per the classification from Central Intelligence Agency guidelines (CIA, 2017). Specifically, the sample comprises 709 hotels, $22.42 \%$ of them are in Southern Europe (Barcelona, Madrid, Lisbon, Milan, Rome), 22.15\% are in Central Europe (Berlin, Prague, Vienna, Zurich) and the remaining $55.43 \%$ are in Western Europe (Brussels, Dublin, Edinburgh, London, Paris). Two independent data sources are used in this study. First, the hotel ratings are collected on the Booking.com website in May 2017. By construction, ratings are showed in the interval [2.5:10] (Mellinas, Maria-Dolores and Garcia, 2015). Second, the hotel performance data are retrieved from STR Share Center, an organization specialized in hotel data storage for academia and business. Revenue per Available Room (RevPAR) represents our proxy for hotel performance, as RevPAR is considered a robust indicator of performance in the hospitality industry (Sainaghi, 2011) and has been widely used in similar research contexts (e.g., Xie et al., 2014; Chen et al, 2016). Table 2 presents the descriptive statistics of the variables included in the analysis.

Table 2. Descriptive statistics

Variable Variable description

Mean

Std. Dev.

Min

Max 


\begin{tabular}{llllll} 
RevPAR & Revenue per available room (Euro) & 161.96 & 116.38 & 29.44 & 1115.26 \\
\hline CLEAN & Rating of Cleanliness & 8.83 & 0.58 & 6.70 & 9.90 \\
COMF & Rating of Comfort & 8.49 & 0.70 & 6.10 & 9.90 \\
LOC & Rating of Location & 9.14 & 0.49 & 6.90 & 9.90 \\
FAC & Rating of Facilities & 8.26 & 0.67 & 6.10 & 9.70 \\
STAFF & Rating of Staff & 8.80 & 0.50 & 7.00 & 9.90 \\
$V F M$ & Rating of Value for money & 7.77 & 0.52 & 6.10 & 9.10 \\
OR & Overall rating & 8.55 & 0.51 & 6.70 & 9.60
\end{tabular}

Source: Authors' elaboration on data retrieved from STR Share Center, and data collected on the Booking.com in May 2017.

In this section, we implement the model presented in section 3 treating hotels as alternatives and individual ratings as criteria. To compare the global score with the interval [2.5:10] as the ratings shown in Booking.com (Mellinas et al., 2015), we normalize the global score (7) as follows:

$$
\text { New Overall Rating } \text { R }_{i}=\left[\left(\frac{\phi\left(a_{i}\right)-\min _{i} \phi\left(a_{i}\right)}{\max _{i} \phi\left(a_{i}\right)-\min _{i} \phi\left(a_{i}\right)}\right) \times 7.5\right]+0.25
$$

Looking at the correlation coefficient between overall rating in Booking.com and the RevPAR, it emerges a spurious correlation, 0.422. Figure 1 presents a graphical representation of the phenomenon, showing the overall rating on the $y$-axis and the RevPAR on the $x$-axis. The dots are the 709 European hotels in the sample, and the blue line is the Local Regression ${ }^{2}$. It is clear that a simple average of individual ratings may increase the overall rating, but may not work as an accurate proxy or predictor ofan hotel performance (RevPAR).

\footnotetext{
${ }^{2}$ We use the ggplot 2 package (Wickham, 2016), in which the function loess is used by default for less than 1,000 observations.
} 


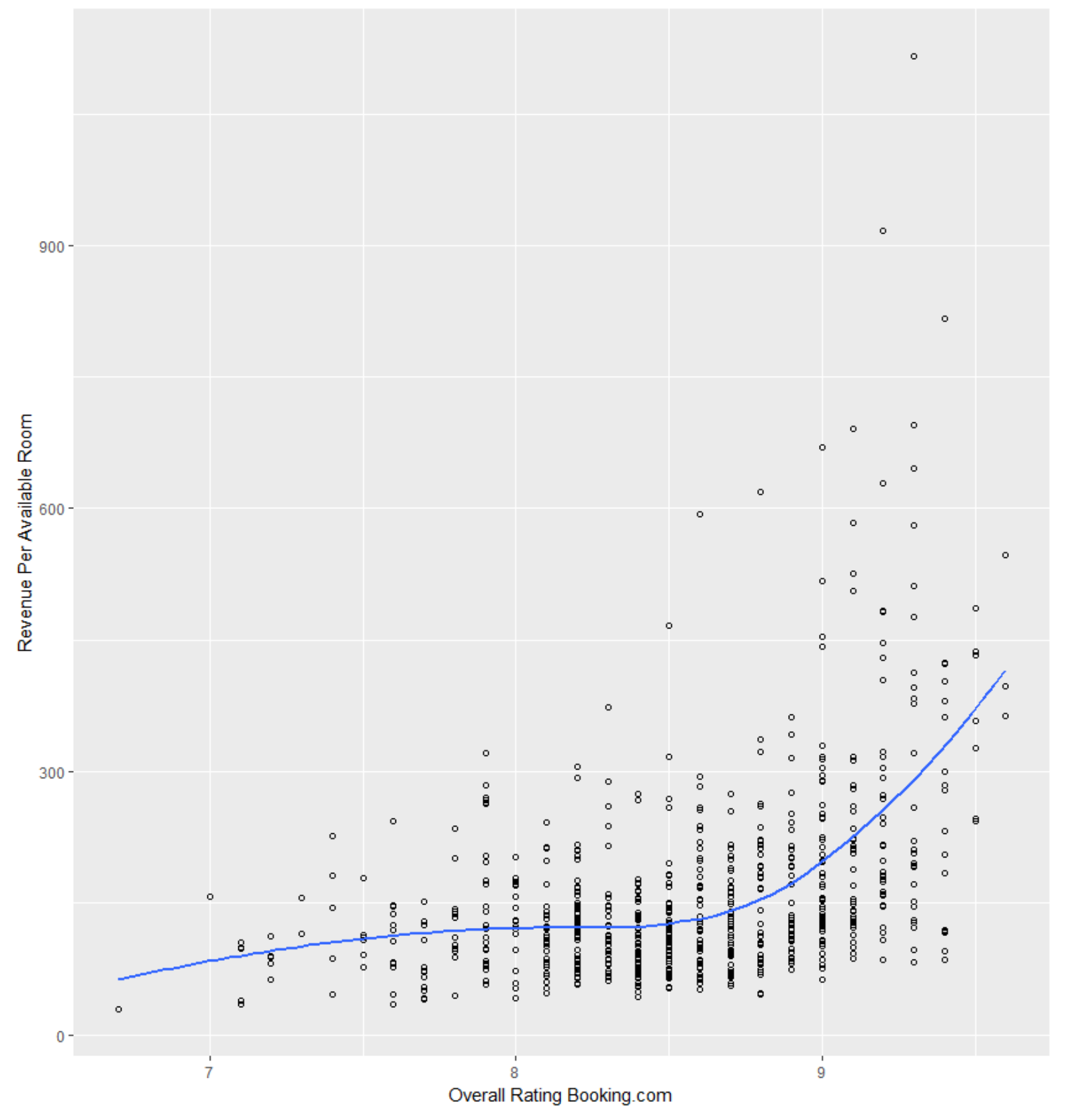

The general low correlation between overall ratings and hotel performance suggests the need to look at the fine-grained relation between individual ratings and RevPAR. When looking at the ratings for the different criteria (See Figure 2), it emerges a relevant differentiation among correlations. In the full dataset the correlation coefficient between ratings and RevPAR is 0.424 for Cleanliness, 0.452 for Comfort, 0.448 for Facilities, 0.390 for Location, 0.439 for Staff, and 0.052 for Value for Money. On average, the Comfort criterion is the most informative, and the Value for Money criterion is the least informative about the performances of hotels, as this attribute has an endogeneous nature. 


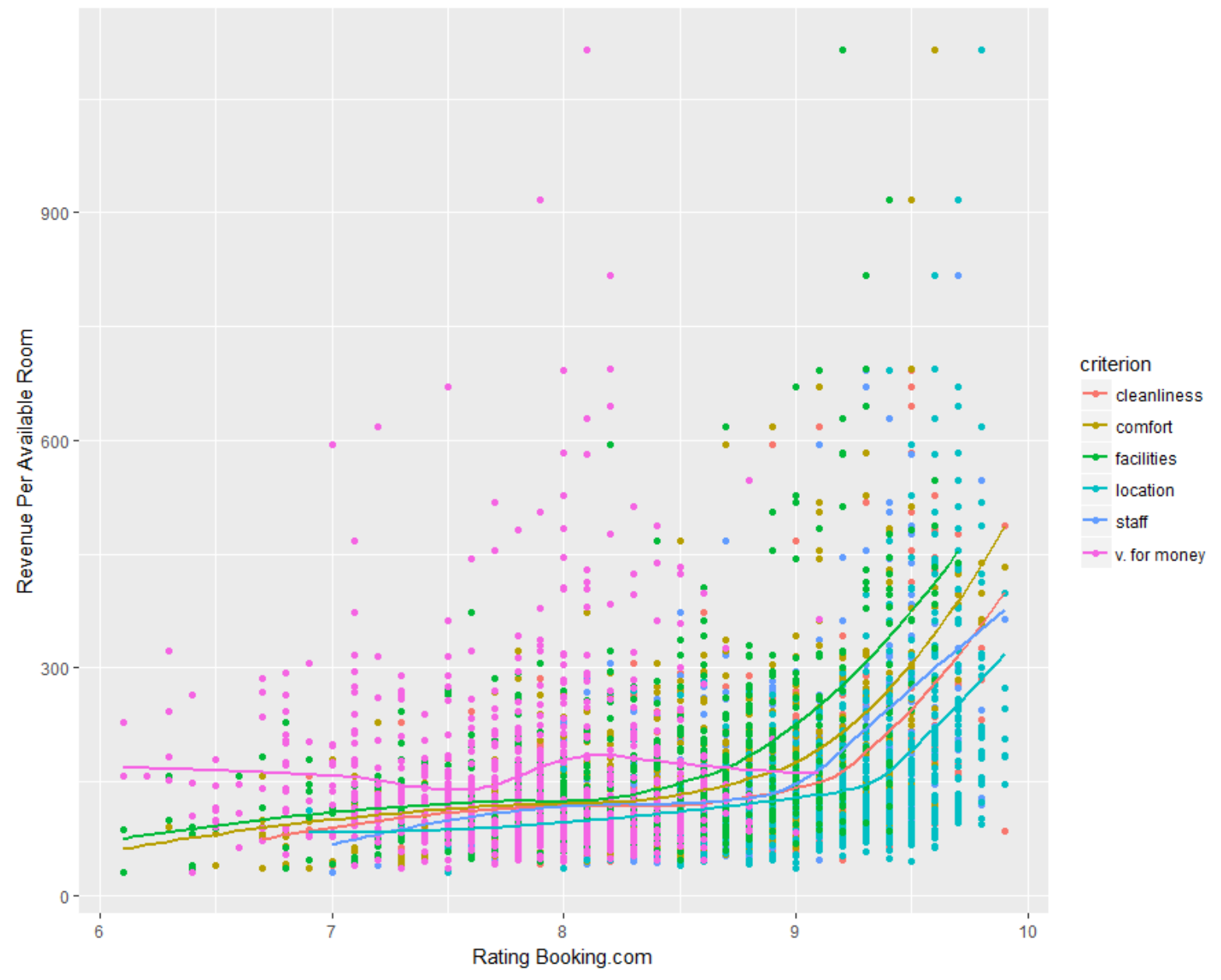

Ignoring these differentiations and all the intangible factors, in Booking.com the overall rating is estimated linearly giving the same weights to all the criteria. This implicitly assumes that all the criteria are similar and linearly contribute in the customer's decision process.

In order to overcome the limitations of the Booking.com overall rating which does not enble to forecast hotel performance, the new overall evaluation presented in Section 3 changes the way the six specific dimensions (Cleanliness, Comfort, Facilities, Location, Staff, and Value for Money) are aggregated. The first stage involves the choice of preference functions. For each criterion, the analysis is replicated with the linear, the level, and the Gaussian preference function, moving the parameters $(p, q, s)$, and choosing the preference function and the parameters that give a result [i.e. unicriterion net flow presented in equation (4)] as much correlated as possible with the RevPAR. Then, starting from the criterion with unicriterion net flow most correlated with RevPAR, the following criteria are added one by one by an iteration algorithm that maximizes the predictive of final overall rating.

Table 3 shows the overall results of the function selection stage. For Cleanliness, Comfort, and Location a level function with both indifference and preference function set to zero is the optimal preference function in order to predict RevPAR. In other words, for these criteria a hotel is totally preferred to another if the difference between ratings is higher than zero. For 
Facilities, Staff, and Value for Money, the optimal preference function is linear, with indifference $0.5,0.2$, and 0.2 , and preference $3.8,0.7$, and 1.3 respectively. In other terms, for the latter three criteria a hotel is indifferent to another under a certain level of difference in rating $(0.5,0.2$ and 0.2$)$, and the preference over hotels increases linearly until the total preference (fixed at 3.8,0.7, and 1.3). These preliminary results confirm that there is not a total linear relation between ratings and performance in any criteria.

Table 3. Preference function choice

\begin{tabular}{lllll}
\hline Criterion & Preference F. & $\mathrm{q}$ & $\mathrm{p}$ & $\mathrm{s}$ \\
\hline Cleanliness & Level & 0 & 0 & $\mathrm{n} / \mathrm{a}$ \\
Comfort & Level & 0 & 0 & $\mathrm{n} / \mathrm{a}$ \\
Location & Level & 0 & 0 & $\mathrm{n} / \mathrm{a}$ \\
Facilities & Linear & 0.5 & 3.8 & $\mathrm{n} / \mathrm{a}$ \\
Staff & Linear & 0.2 & 0.7 & $\mathrm{n} / \mathrm{a}$ \\
Value for Money & Linear & 0.2 & 1.3 & $\mathrm{n} / \mathrm{a}$ \\
\hline
\end{tabular}

The next sub-section introduces the new overall rating.

\subsection{The proposed overall rating on the full sample}

As reported in Section 3, the estimates in this study are based on a three stages analysis. In the first stage, the unicriterion net flows are estimated by PROMETHEE on the ratings for the six different criteria in the Booking.com. In the second stage, the weights are estimated by linear regression between unicriterion net flows and RevPAR. In the final stage, a new overall rating is estimated by the weighted sum of the unicriterion net flows multiplied by weights from the regression (the coefficients). Table 4 presents the results of the linear regression (6) between unicriterion net flows and RevPAR.

Table 4. Regression coefficient between unicriterion net flows and the RevPAR on the full sample

\begin{tabular}{|c|c|c|c|c|c|}
\hline & Estimate & Std. Error & $\mathrm{t}$ value & $\operatorname{Pr}(>|t|)$ & \\
\hline (Intercept) & 161.964 & 3.146 & 51.484 & 0.000 & $* * *$ \\
\hline Cleanliness & 0.042 & 0.027 & 1.518 & 0.130 & \\
\hline Comfort & 0.079 & 0.027 & 2.943 & 0.003 & $* *$ \\
\hline Location & 0.059 & 0.010 & 6.151 & 0.000 & $* * *$ \\
\hline Facilities & 0.412 & 0.096 & 4.284 & 0.000 & $* * *$ \\
\hline Staff & 0.081 & 0.022 & 3.684 & 0.000 & $* * *$ \\
\hline Value for Money & -0.362 & 0.021 & -17.230 & 0.000 & $* * *$ \\
\hline
\end{tabular}

Table 4 shows that on the full sample there are significant and positive coefficients between unicriterion net flows and RevPAR, in five of the six criteria considered: Cleanliness, Comfort, Location, Facilities, and Staff. The coefficient for unicriterion net flow estimated on Value for 
Money is instead negative. The most important criterion in the customer's decision-making process is Facilities, which has the highest weight in Table 4.

The estimated weights in Table 4 are then used in the new overall rating estimated by the equations (7) and (8). The new overall rating captures the multi-dimensionality of online ratings. Indeed, it accounts for the differences in the preference function for each individual rating. In addition, it points at the need of a dynamic evaluation that can be constantly updated by changing the weights of individual ratings.

The proposed measure correlates with the RevPAR more than the correlation between each singular criterion and the RevPAR, and by construction more than the correlation between the overall evaluation in Booking.com and the RevPAR. The correlation coefficient between our overall rating and the RevPAR is 0.697 , while the correlation coefficient between overall ranking in Booking.com and the RevPAR is 0.414. In Figure 3 we show a graphical representation of the model accuracy. The red dots represent the relation between RevPAR and overall ratings in Booking.com, while the blue dots represent the relation between RevPAR and overall ratings estimated with the algorithm we propose. This graphical comparison clearly shows that the overall rating proposed in this study better captures the multi-faced nature of the phenomenon. 
Figure 3. The relation between overall ratings (Booking.com and the one proposed) and the RevPAR in 709 European hotels

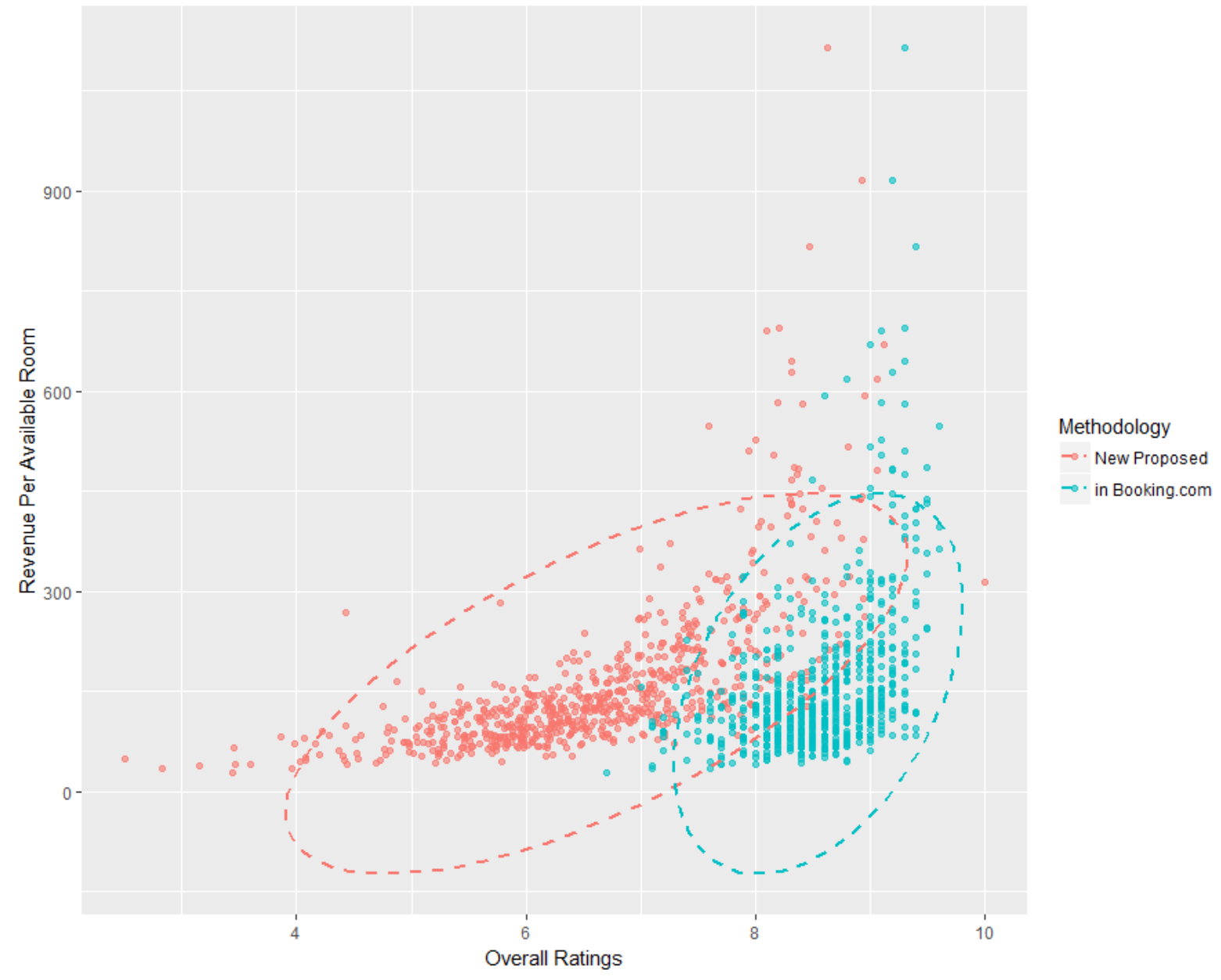

\subsection{Robustness check}

As robustness check, this sub-section includes the estimation of the overall rating just by regressing ratings on RevPar. In other words, to estimate the weights given to each criterion, we solve the new regression (9):

$$
\operatorname{RevPAR}=\alpha+\vartheta \cdot w+\varepsilon
$$

where, differently from (6), $\vartheta$ is now the matrix with the ratings. Specifically, we exclude the PROMETHEE procedure and we relax just the assumption of equal weights among criteria in Booking.com.

The results of regression (9) on the full dataset are in Table 5. Interestingly, the significance of coefficients in Table 5 are quite in line with coefficients in Table 4, although they refer directly to the rating, while coefficients in Table 4 refer to unicriterion net flows.

Table 5. Regression coefficient between ratings and the RevPAR on the full sample 


\begin{tabular}{|c|c|c|c|c|c|}
\hline & Estimate & Std. Error & $\mathrm{t}$ value & $\operatorname{Pr}(>|t|)$ & \\
\hline (Intercept) & -514.439 & 73.971 & -6.955 & 0.000 & $* * *$ \\
\hline Cleanliness & 1.936 & 19.373 & 0.100 & 0.920 & \\
\hline Comfort & 48.628 & 19.356 & 2.512 & 0.012 & $*$ \\
\hline Location & 41.078 & 8.029 & 5.116 & 0.000 & $* * *$ \\
\hline Facilities & 62.592 & 20.885 & 2.997 & 0.003 & $* *$ \\
\hline Staff & 69.934 & 14.432 & 4.846 & 0.000 & $* * *$ \\
\hline Value for Money & -162.423 & 9.844 & -16.500 & 0.000 & $* * *$ \\
\hline
\end{tabular}

In line with Table 4, in Table 5 there are significant and positive coefficients between ratings and RevPar, in Cleanliness, Comfort, Location, Facilities, and Staff. Moreover, the coefficient for Value for Money is again negative. Finally, Facilities and Staff are the most significant criteria.

In Table 6, the residual standard error obtained by regression (9) is compared with the residual standard error obtained with the equation (6).

Table 6. Residual Standard Errors (RSE)

\begin{tabular}{rrr}
\hline & Equation (6) & Regression (9) \\
\hline RSE & 79.77 & 85.94 \\
\hline
\end{tabular}

The difference in the Residual standard errors clearly reveals that the indicator obtained just regressing the ratings and using weights for the overall rating is less predictive than the overall rating obtained with the newly prosposed procedure in section 4.1. That is because the use of PROMETHEE does not only introduce weighting, but it also allows to relax the linearity assumption on preference functions, and includes pairwise comparisons instead of overall utility.

More importantly, the simple average proposed in Booking.com, as well as the model in equation (9), can be considered as an additive aggregation method. As mentioned in the methodology section, the main problem with averages is the compensation across scores. Key information can be lost by such aggregation. This is not the case with the PROMETHEE method, because such trade-offs are avoided. The advantage of the PROMETHEE method is to use the partial aggregation approach which compares the actions pairwise and enables to check whether one action clearly outranks the other or not. Additionally, PROMETHEE methods do not allow compensation between criteria. 


\section{Discussion and conclusion}

Ratings have become a central pillar in online purchase decisions. Online review platforms typically summarize customers' opinions in an overall rating by aggregating various criteria that reflect the product dimensions. However, research on the key criteria that contribute to revenue maximization is at a moot point. Several studies in the field rely on average overall ratings to explain the effect of online ratings on performance (e.g., Öğüt and Taş, 2012; Viglia et al., 2016). To overcome this limitation, the authors present a new method to summarize individual ratings. Specifically, the present study proposes an innovative weighting mechanism. This method offers a valuable application for practitioners operating in ecommerce, as it updates based on new customers' evaluations and performance data.

The superiority of the model proposed in this study relies on the relaxation of some assumptions made by the arithmetic average approach, i.e., equal weights for the different attributes, overall utility and a linear preference function for all of them. This new method reflects the customers' decision process in a more accurate way, including different weights that reflect the higher importance of some attributes over other ones and proposing different preference functions for each attribute. The empirical application of the model is based on the aggregation of individual criteria in Booking.com using the PROMETHEE method, a multi-criteria decision analysis method that allows the inclusion of information from the decision-maker. Since being introduced by Brans \& Vincke in 1985, researchers have successfully applied PROMETHEE in many fields. However, the main limitation in the traditional business field is that this technique needs exogenous weights and an exogenous preference function (Behzadian et al., 2010). The present study proposes an innovative PROMETHEE that estimates preference functions and weights in a data-driven process and determines the effective criteria for revenue maximization in the hospitality industry.

Results highlight the key role played by Facilities and Staff for revenue maximization, two attributes that remain central also in the robustness check. The findings also show that the review evaluation of the location is not particularly key when it comes to hotel performance. Although previous research argues that hotel Location plays a leading role in customer satisfaction (Li et al., 2015; Yang, Mao \& Tang, 2018) and hotel rates (Lee \& Yang, 2011), this paper suggests that the effect on hotel actual revenues (RevPAR) is limited. A possible explanation is that this study focuses on the rating for the location given by customers instead of the actual location. Customers already know the hotel location when they choose the hotel, so their evaluation might refer to more intangible aspects of the location (e.g., street noise) that were difficult to assess prior to the hotel visit.

These findings provide theoretical implications that guide future studies on online ratings. Consistently with Park and Nicolau (2017), who suggest to carefully consider the impact of separate attributes, this study provides a methodological contribution in the construction of overall ratings, offering a new tool. The results support the superiority of the use of different preference functions for different product attributes with respect to traditional regressions. In particular, the evidence supports the idea of adaptive decision behaviour, i.e., information 
processing is different depending on the importance of the elements in a choice alternative (Park \& Nicolau, 2017). As cognitive effort-reducing heuristics, overall ratings facilitate the construction of the consideration set in the hotel decision making process ( $\mathrm{Hu}, \mathrm{Koh} \& \mathrm{Reddy}$, 2014; Jones \& Chen, 2011). Individual ratings reflect the attributes that customers consider relevant for the hotel choice. Through the use of econometric modelling it is possible to offer a more accurate overall rating that accounts for the importance of the single individual attributes. This would result in more informed decision for customers and improved RevPAR for hotels.

Building on Zhang et al. (2017), who point out the need to consider the interdependence among criteria, this paper also discusses the peculiar contribution of Value for Money individual ratings to the overall score. The findings reveal that the effect of Value for Money on revenues is negative. This is in line with previous studies that find evidence of a negative effect of Value for Money on RevPAR (Xie et al., 2014). The negative contribution of Value for Money in terms of revenue maximization reflects the endogenous nature of this dimension. Specifically, Value for Money is a proxy for consumer's surplus and therefore might erode the producer's surplus.

From a managerial perspective, this approach helps operators to better understand the attributes that play a leading role in terms of revenue maximization. Improving those dimensions that are important to customers will be beneficial to hotels as long as the improvements are costefficient. In other words, customers' priorities should be balanced against the economic costs to ensure the profitability of the investments. For instance, improving facilities, which appears to be essential for revenue maximization, might be more costly than improving cleanliness. Interestingly, the study shows the central role of Staff in revenue maximization, which supports recent evidence on the importance of employee emotional intelligence in terms of revenue maximization (Matute \& Palau, 2018). In sum, after considering which dimensions customers rank higher, each hotel should conduct careful cost benefit evaluations to decide on which attributes it should invest resources and how best those attributes could be improved.

The present study is not without limitations. First, it considers a single online platform (i.e. Booking.com). One possible extension is to investigate whether the information provided by third-party web sites (e.g., Tripadvisor.com) affects hotel performance in the same way. Second, the empirical model does not use a time parameter. Although the cross-section data set in this study is adequate to address the research goal, interesting conclusions could be drawn if the study accounted for changes in online ratings over time. Finally, the empirical analysis is based only on a single industry. The multidimensionality of ratings is common in many fields. For example, in the education sector, every year the university guides rank universities by means of ratings in different criteria such as student satisfaction, research quality, completion rate etc. The methodology used to rank universities is usually a simple weighted sum of the criteria which aggregation is fully compensatory and does not differentiate between universities having strengths in different areas (Ishizaka et al. 2017). The way by which the different criteria contribute to the number of new enrolled students is ignored by these rankings. Marketing is another promising area for PROMETHEE, given that non-linear preferences of customers need to be modelled. 


\section{References}

Ahn, D., Park, H. \& Yoo, B. (2017). Which Group Do You Want to Travel with? A Study of Rating Differences among Groups in Online Travel Reviews. Electronic Commerce Research and Applications, 25, 99-126.

Akincilar, A., \& Dagdeviren, M. (2014). A hybrid multi-criteria decision making model to evaluate hotel websites. International Journal of Hospitality Management, 36, 263-271.

Baek, H., Ahn, J., \& Choi, Y. (2012). Helpfulness of online consumer reviews: Readers' objectives and review cues. International Journal of Electronic Commerce, 17(2), 99-126.

Behzadian, M., Kazemzadeh, R. B., Albadvi, A., \& Aghdasi, M. (2010). PROMETHEE: A comprehensive literature review on methodologies and applications. European Journal of Operational Research, 200(1), 198-215.

Bettman, J. R., Luce, M. F., \& Payne, J. W. (1998). Constructive consumer choice processes. Journal of Consumer Research, 25(3), 187-217.

Booking.com. (2017). About Booking.com. Available at: http://www.booking.com/content/about.html Accessed 25 January 2017

Brans, J. P., \& De Smet, Y. (2016). PROMETHEE methods. In Multiple Criteria Decision Analysis (pp. 187-219). Springer, New York, NY.

Brans, J. P., \& Vincke, P. (1985). Note-A Preference Ranking Organisation Method: (The PROMETHEE Method for Multiple Criteria Decision-Making). Management Science, 31(6), 647-656.

Brans, J. P., Vincke, P., \& Mareschal, B. (1986). How to select and how to rank projects: The PROMETHEE method. European Journal of Operational Research, 24(2), 228-238.

Cantallops, A. S., \& Salvi, F. (2014). New consumer behavior: A review of research on eWOM and hotels. International Journal of Hospitality Management, 36, 41-51.

Casalo, L. V., Flavian, C., Guinaliu, M., \& Ekinci, Y. (2015). Do online hotel rating schemes influence booking behaviors?. International Journal of Hospitality Management, 49, 2836.

Chatterjee, P. (2001). Online reviews: do consumers use them? Advances in Consumer Research, 28, 129-133.

Chen, C. M., Lin, Y. C., Chi, Y. P., \& Wu, S. C. (2016). Do competitive strategy effects vary across hotel industry cycles?. International Journal of Hospitality Management, 54, 104106.

Cheung, C. M., \& Thadani, D. R. (2012). The impact of electronic word-of-mouth communication: A literature analysis and integrative model.Decision Support Systems, 54(1), 461-470. 
CIA. (2017). Central Intelligence Agency classification 2017. Available at: https://www.cia.gov/library/publications/the-world-factbook/docs/refmaps.html Accessed 25 May 2017.

Costanza, R., Daly, L., Fioramonti, L., Giovannini, E., Kubiszewski, I., Mortensen, L. F., Wilkinson, R. (2016). Modelling and measuring sustainable wellbeing in connection with the UN Sustainable Development Goals. Ecological Economics, 130, 350-355.

de Oliveira Santos, G. E. (2016). Worldwide hedonic prices of subjective characteristics of hostels. Tourism Management, 52, 451-454.

Decancq, K. and Lugo, M. A. (2013). Weights in Multidimensional Indices of Wellbeing: An Overview. Econometric Reviews, 32(1):7-34.

Dellarocas, C. (2003). The digitization of word of mouth: Promise and challenges of online feedback mechanisms. Management Science, 49(10), 1407-1424.

Ert, E., \& Fleischer, A. (2016). Mere position effect in booking hotels online. Journal of Travel Research, 55(3), 311-321.

Falk, M., \& Hagsten, E. (2015). Modelling growth and revenue for Swedish hotel establishments. International Journal of Hospitality Management, 45, 59-68.

Fang, B., Ye, Q., Kucukusta, D., \& Law, R. (2016). Analysis of the perceived value of online tourism reviews: Influence of readability and reviewer characteristics. Tourism Management, 52, 498-506.

Filieri, R., \& McLeay, F. (2014). E-WOM and accommodation: An analysis of the factors that influence travelers' adoption of information from online reviews. Journal of Travel Research, 53(1), 44-57.

Greco, S., Figueira, J., \& Ehrgott, M. (2005). Multiple criteria decision analysis. Springer's International series.

Greco, S., Ishizaka, A., Tasiou, M., \& Torrisi, G. (2018). On the methodological framework of composite indices: a review of the issues of weighting, aggregation, and robustness. Social Indicators Research, 1-34.

Heras-Saizarbitoria, I., Arana, G., \& Boiral, O. (2015). Do ISO 9001-certified hotels get a higher customer rating than non-certified ones?. International Journal of Hospitality Management, 51, 138-146.

Hu, N., Koh, N. S., \& Reddy, S. K. (2014). Ratings lead you to the product, reviews help you clinch it? The mediating role of online review sentiments on product sales. Decision Support Systems, 57, 42-53.

Ishizaka, A., \& Nemery, P. (2013). Multi-criteria decision analysis: methods and software. John Wiley \& Sons. 
Ishizaka, A., Resce, G., \& Mareschal, B. (2017). Visual management of performance with PROMETHEE productivity analysis. Soft Computing, 1-14.

Jones, P., \& Chen, M. M. (2011). Factors determining hotel selection: Online behaviour by leisure travellers. Tourism and Hospitality Research, 11(1), 83-95.

Kim, W. G., Lim, H., \& Brymer, R. A. (2015). The effectiveness of managing social media on hotel performance. International Journal of Hospitality Management, 44, 165-171.

Kim, B., Kim, S., \& Heo, C. Y. (2016). Analysis of satisfiers and dissatisfiers in online hotel reviews on social media. International Journal of Contemporary Hospitality Management, 28(9), 1915-1936.

Ladhari, R., \& Michaud, M. (2015). eWOM effects on hotel booking intentions, attitudes, trust, and website perceptions. International Journal of Hospitality Management, 46, 36-45.

Lee, S. K., \& Jang, S. (2011). Room rates of US airport hotels: examining the dual effects of proximities. Journal of Travel Research, 50(2), 186-197.

Lee, M., \& Youn, S. (2009). Electronic word of mouth (eWOM) How eWOM platforms influence consumer product judgement. International Journal of Advertising, 28(3), 473499.

Liang, S. W-J., Ekinci, Y., Occhiocupo, N., \& Whyatt, G. (2013). Antecedents of travellers' electronic word-of-mouth communication. Journal of Marketing Management, 29(5-6), 584-606.

Litvin, S. W., Goldsmith, R. E., \& Pan, B. (2008). Electronic word-of-mouth in hospitality and tourism management. Tourism Management, 29(3), 458-468.

Li, G., Law, R., Vu, H. Q., Rong, J., \& Zhao, X. R. (2015). Identifying emerging hotel preferences using Emerging Pattern Mining technique. Tourism Management, 46, 311321.

Liu, Z., \& Park, S. (2015). What makes a useful online review? Implication for travel product websites. Tourism Management, 47, 140-151.

Matute, J., \& Palau, R. (2018). Beyond chemistry. Emotional competence in personalized services. Journal of Services Marketing, forthcoming.

Mauri, A. G., \& Minazzi, R. (2013). Web reviews influence on expectations and purchasing intentions of hotel potential customers. International Journal of Hospitality Management, 34, 99-107.

Mellinas, J. P., María-Dolores, S. M. M., \& García, J. J. B. (2015). Booking. com: The unexpected scoring system. Tourism Management, 49, 72-74.

Munda, G. (2012). Choosing aggregation rules for composite indicators. Social Indicators Research, 109(3), 337-354. 
Munda, G., \& Nardo, M. (2009). Noncompensatory/nonlinear composite indicators for ranking countries: A defensible setting. Applied Economics, 41(12), 1513-1523.

Nardo, M., Saisana, M., Saltelli, A., Tarantola, S., Hoffman, A., Giovannini, E. (2008). Handbook on constructing composite indicators. Paris: OECD-JRC.

Nieto-García, M., Muñoz-Gallego, P. A., \& González-Benito, Ó. (2017). Tourists’ willingness to pay for an accommodation: The effect of eWOM and internal reference price. International Journal of Hospitality Management, 62, 67-77.

Öğ̈̈t, H., \& Onur Taş, B. K. (2012). The influence of internet customer reviews on the online sales and prices in hotel industry. The Service Industries Journal, 32(2), 197-214.

Park, S., \& Nicolau, J. L. (2017). Effects of general and particular online hotel ratings. Annals of Tourism Research, 62, 114-116.

Paruolo, P., Saisana, M., and Saltelli, A. (2013). Ratings and rankings: voodoo or science? Journal of the Royal Statistical Society: Series A (Statistics in Society), 176(3):609634.

Pera, R., \& Viglia, G. (2016). Exploring how video digital storytelling builds relationship experiences. Psychology \& Marketing, 33(12), 1142-1150.

Petty, R. E., Cacioppo, J. T., \& Goldman, R. (1981). Personal involvement as a determinant of argument-based persuasion. Journal of Personality and Social Psychology, 41(5), 847.

Ramanathan, U., \& Ramanathan, R. (2011). Guests' perceptions on factors influencing customer loyalty: An analysis for UK hotels. International Journal of Contemporary Hospitality Management, 23(1), 7-25.

Rhee, H. T., \& Yang, S. B. (2015). Does hotel attribute importance differ by hotel? Focusing on hotel star-classifications and customers' overall ratings. Computers in Human Behavior, 50, 576-587.

Sainaghi, R. (2011). RevPAR determinants of individual hotels: evidences from Milan. International Journal of Contemporary Hospitality Management, 23(3), 297-311.

Schuckert, M., Liu, X., \& Law, R. (2016). Insights into suspicious online ratings: direct evidence from TripAdvisor. Asia Pacific Journal of Tourism Research, 21(3), 259-272.

Sirakaya, E., \& Woodside, A. G. (2005). Building and testing theories of decision making by travellers. Tourism management, 26(6), 815-832.

Sparks, B. A., \& Browning, V. (2011). The impact of online reviews on hotel booking intentions and perception of trust. Tourism Management, 32(6), 1310-1323.

The Economist (2017). The Priceline party. The world's largest online-travel company, Available at: https://www.economist.com/business/2017/07/29/the-worlds-largestonline-travel-company Accessed 24 June 2018 
Top 15 most popular travel websites (2017). Top 15 most popular travel websites. Available at: http://www.ebizmba.com/articles/travel-websites Accessed 25 May 2017.

Tversky, A. \& Kahneman, D. (1975). Judgment under uncertainty: Heuristics and biases. In Utility, probability, and human decision making, Springer.

Viglia, G., Minazzi, R., \& Buhalis, D. (2016). The influence of e-word-of-mouth on hotel occupancy rate. International Journal of Contemporary Hospitality Management, 28(9), 2035-2051.

Wickham, H. (2016). ggplot2: elegant graphics for data analysis, Springer.

Xie, K. L., Zhang, Z., \& Zhang, Z. (2014). The business value of online consumer reviews and management response to hotel performance. International Journal of Hospitality Management, 43, 1-12.

Yang, Y., Mao, Z., \& Tang, J. (2018). Understanding guest satisfaction with urban hotel location. Journal of Travel Research, 57(2), 243-259.

Yang, Y., Park, S., \& Hu, X. (2018). Electronic word of mouth and hotel performance: A metaanalysis. Tourism Management, 67, 248-260.

Ye, Q., Law, R., \& Gu, B. (2009). The impact of online user reviews on hotel room sales. International Journal of Hospitality Management, 28(1), 180-182.

Ye, Q., Law, R., Gu, B., \& Chen, W. (2011). The influence of user-generated content on traveler behavior: An empirical investigation on the effects of e-word-of-mouth to hotel online bookings. Computers in Human Behavior, 27(2), 634-639.

Zhang, H. Y., Ji, P., Wang, J. Q., \& Chen, X. H. (2017). A novel decision support model for satisfactory restaurants utilizing social information: A case study of TripAdvisor. com. Tourism Management, 59, 281-297.

Zhang, Z., Ye, Q., \& Law, R. (2011). Determinants of hotel room price: An exploration of travelers' hierarchy of accommodation needs. International Journal of Contemporary Hospitality Management, 23(7), 972-981.

Zhao, X., Wang, L., Guo, X., \& Law, R. (2015). The influence of online reviews to online hotel booking intentions. International Journal of Contemporary Hospitality Management, 27(6), 1343-1364.

Zhu, F., \& Zhang, X. (2010). Impact of online consumer reviews on sales: The moderating role of product and consumer characteristics. Journal of Marketing, 74(2), 133-148. 